\title{
The Role of Tropical, Midlatitude, and Polar Cloud-Radiative Changes for the Midlatitude Circulation Response to Global Warming $\mathscr{A}$
}

\author{
NiCOLE ALBERN \\ Institute of Meteorology and Climate Research-Department Troposphere Research, \\ Karlsruhe Institute of Technology, Karlsruhe, Germany
}

AIKO VOIGT

Institute of Meteorology and Climate Research-Department Troposphere Research, Karlsruhe Institute of Technology, Karlsruhe, Germany, and Lamont-Doherty Earth Observatory, Columbia University, New York, New York

\section{DAVID W. J. THOMPSON}

Department of Atmospheric Science, Colorado State University, Fort Collins, Colorado

JOAQUIM G. PINTO

Institute of Meteorology and Climate Research-Department Troposphere Research, Karlsruhe Institute of Technology, Karlsruhe, Germany

(Manuscript received 6 February 2020, in final form 17 June 2020)

\begin{abstract}
Previous studies showed that global cloud-radiative changes contribute half or more to the midlatitude atmospheric circulation response to global warming. Here, we investigate the relative importance of tropical, midlatitude, and polar cloud-radiative changes for the annual-mean, wintertime, and summertime circulation response across regions in AMIP-like simulations. To this end, we study global warming simulations from the ICON model run with the cloud-locking method and prescribed sea surface temperatures, which isolate the impact of changes in atmospheric cloud-radiative heating. Tropical cloud changes dominate the global cloud impact on the $850 \mathrm{hPa}$ zonal wind, jet strength, and storm track responses across most seasons and regions. For the jet shift, a more diverse picture is found. In the annual mean and DJF, tropical and midlatitude cloud changes contribute substantially to the poleward jet shift in all regions. The poleward jet shift is further supported by polar cloud changes across the Northern Hemisphere but not in the Southern Hemisphere. In JJA, the impact of regional cloud changes on the jet position is small, consistent with an overall small jet shift during this season. The jet shift can be largely understood via the anomalous atmospheric cloud-radiative heating in the tropical and midlatitude upper troposphere. The circulation changes are broadly consistent with the influence of cloud-radiative changes on upper-tropospheric baroclinicity and thus the mean potential energy available for conversion into eddy kinetic energy. Our results help to explain the jet response to global warming and highlight the importance of tropical and midlatitude cloud-radiative changes for this response.
\end{abstract}

\section{Introduction}

The midlatitude, eddy-driven jet streams are an important component of the large-scale atmospheric circulation. They develop in regions with strong horizontal

Supplemental information related to this paper is available at the Journals Online website: https://doi.org/10.1175/JCLI-D-20-0073.s1.

Corresponding author: Nicole Albern, nicole.albern@kit.edu temperature and pressure gradients, and may be viewed as including two components: 1) a surface wind component that is maintained by the convergence of eddy momentum fluxes aloft and 2) a vertically varying component that is mandated by thermal wind balance (Vallis 2017). The eddy-driven jets have their largest amplitude in the storm track regions over the oceans (Peixoto and Oort 1992).

In response to global warming, the midlatitude circulation is expected to change due to modifications in 
the thermal structure of the atmosphere. Climate models project a poleward shift of the zonal-mean midlatitude jet streams [see the review by Vallis et al. (2015), and references therein]. This general result was found both for idealized and more realistic coupled model studies (e.g., Butler et al. 2010; Barnes and Polvani 2013; Kushner et al. 2001). However, the magnitude of the jet response differs between models, seasons, and regions. While for the Southern Hemisphere a poleward shift and strengthening of the jet stream is clear in all seasons (Simpson et al. 2014), the wintertime changes over the North Atlantic, for example, resemble rather a downstream extension and intensification of the jet than a poleward shift (Woollings et al. 2012; Zappa et al. 2015).

The dominant physical mechanisms contributing to a jet shift and/or strengthening are not clear (Bony et al. 2015; Shaw et al. 2016). Possible mechanisms contributing to the jet response include changes in upper- and/ or lower-tropospheric temperature gradients (Butler et al. 2010; Harvey et al. 2015; Lu et al. 2008; Yin 2005), a rise of the tropopause (Yin 2005; Lorenz and DeWeaver 2007), an increase in the static stability of the subtropical and midlatitudinal troposphere ( $\mathrm{Lu}$ et al. 2008), increases in the eddy length scale (Kidston et al. 2010), increased (Chen et al. 2008) or reduced (Kidston et al. 2011) eddy phase speeds, and changes in the index of refraction for wave propagation (Simpson et al. 2009). The recently published review by Shaw (2019) gives an overview of the possible mechanisms, including additionally the effects of increases in latent heat release in the upper-tropospheric tropics, radiative cooling in the stratosphere, increases in specific humidity, and the impact of cloud-radiative changes.

It is generally accepted that the changes in uppertropospheric temperature gradients and baroclinicity play an important role for the jet shifts. For example, the idealized study by Butler et al. (2010) provided evidence that upper-tropospheric tropical heating leads to a poleward jet shift. The authors further showed that low-level polar warming leads to an equatorward shift of the jet stream. Harvey et al. (2015) showed that while the jet stream and storm track responses to climate change are primarily associated with the upper-tropospheric temperature gradient change, changes of the lower-tropospheric temperature gradients can also be determinant, notably for the North Atlantic Ocean basin.

Several recent studies discussed the role of clouds and their radiative interactions with the atmospheric circulation within the context of climate change [e.g., the review by Ceppi and Hartmann (2015), and references therein]. Most of these studies used the cloud-locking method to investigate the impact of cloud-radiative changes on the circulation response to global warming in different model setups. Voigt and Shaw $(2015,2016)$ found evidence that changes in cloud-radiative properties support the poleward jet shift in idealized aquaplanet simulations with prescribed sea surface temperatures (SST). Similar results were found by Ceppi and Hartmann (2016) in idealized aquaplanet simulations with a slab ocean. More recent studies found important contributions of cloudradiative changes to the jet response in more realistic Atmospheric Model Intercomparison Project (AMIP)-like simulations (Gates 1992) with prescribed SST or a slab ocean (Ceppi and Shepherd 2017; Albern et al. 2019; Voigt et al. 2019). Most recently, Voigt and Albern (2019) showed that the cloud-locking method is to date the most appropriate method to study the impact of cloud-radiative changes on the circulation response to global warming.

Voigt et al. (2019) introduced the concept of the atmospheric and surface pathways of the cloud-radiative impact. The surface pathway arises from a cloud-induced change in SST (via changes in surface cloud-radiative heating), whereas the atmospheric pathway arises from the fact that cloud-radiative changes can impact the circulation even in the absence of SST changes (via changes in atmospheric cloud-radiative heating and atmospheric temperature). Voigt et al. (2019) found that the atmospheric pathway is, at least in the one model considered, as important as the surface pathway. Recently, Albern et al. (2019) showed that in an AMIP-like setup the impact of global cloud-radiative changes via the atmospheric pathway on the jet stream response is significant and largely zonally symmetric and does not strongly depend on the season and pattern of SST increase but varies across ocean basins. Investigating the responses in three different models, Voigt et al. (2019) found substantial spread in the response, as the magnitude of the change in atmospheric cloud-radiative heating and its impact on the circulation response varies across models.

To make progress on the cloud-jet problem, it is necessary to understand which regional cloud-radiative changes are most important for the global cloud-radiative impact. Voigt and Shaw (2016) investigated the impact of tropical, midlatitude, and polar cloud-radiative changes in an aquaplanet setup and found that tropical and midlatitude cloud-radiative changes in the upper troposphere contribute about equally to the poleward jet shift in two models, whereas the impact of polar cloud-radiative changes was smaller and not robust in the two models. While this study focused on the aquaplanet setup, there is still a large gap in understanding which regional cloudradiative changes are dominant in an AMIP-like setup including continents, sea ice, and a seasonal cycle. In this study, we address the role of regional cloud-radiative changes in an AMIP-like setup, and use the ICON model (Zängl et al. 2015) with prescribed SST and the 
cloud-locking method to quantify the role of tropical, midlatitude, and polar cloud-radiative changes across seasons and regions. We identify which clouds are most important when continents, sea ice, and a seasonal cycle are included in the simulations. The main research questions are as follows:

1) Are tropical, midlatitude, or polar cloud-radiative changes more important for the global cloud impact on the zonal wind, jet stream, and storm track responses to global warming? Do the results depend on the season and the region?

2) Can we understand the circulation impact of regional cloud-radiative changes on the zonal wind and jet responses based on (established) dynamical arguments?

The structure of this paper is as follows. In section 2, we will introduce the modeling setup, the circulation metrics, and our measure for significance. We show the response of the midlatitude jet streams to regional cloud-radiative changes in section 3 , and link the jet response to changes in upper-tropospheric baroclinicity in section 4 . We conclude with the main results and an outlook in section 5 .

\section{Model simulations and methods}

\section{a. ICON model simulations with the cloud-locking method}

We use the atmospheric component of the ICOsahedral Non-hydrostatic (ICON) model (Zängl et al. 2015, version 2.1.00) with the physics package developed for numerical weather prediction. We run the model with AMIP-like boundary conditions, that is, with present-day continents, sea ice, and a seasonal cycle, and prescribed climatological SST, and mimic global warming by a uniform $4 \mathrm{~K}$ SST increase. In each simulation, we prescribe the present-day sea ice to the model that was obtained by calculating a multiyear monthly mean over the AMIP period (19792008; Gates 1992). Sea ice is set to the same values in all simulations to isolate the effect of increased SST. The details of the model setup, such as resolution and further boundary conditions, are provided in Albern et al. (2019).

We apply the cloud-locking method to determine how much of the circulation response to global warming can be attributed to changes in cloud-radiative properties, and focus on the atmospheric pathway of the cloudradiative impact (Voigt et al. 2019). Note that water vapor and surface albedo are not locked in our simulations, but that their effects were investigated in previous studies (e.g., Graversen and Wang 2009; Mauritsen et al. 2013; Voigt and Shaw 2015; Ceppi and Shepherd 2017).
Albern et al. (2019) showed that ICON simulates a reasonable circulation response to global warming with interactive clouds, and that this is captured by simulations with locked clouds. Thus, the residual of the cloudlocking method is small, except for the spring season [March to May; see Albern et al. (2019) for a detailed discussion of the residual]. Additionally, Albern et al. (2019) found that the impact of cloud-radiative changes on the jet stream response to global warming is largely independent of the pattern of the SST increase. We therefore focus on the idealized global warming setup of a uniform $4 \mathrm{~K}$ SST increase in this study.

The total circulation response for any variable $X$ is given by

$$
\Delta X=X_{4 \mathrm{~K}}-X_{\mathrm{CTL}}=X_{\mathrm{T} 2 \mathrm{C} 2}-X_{\mathrm{T} 1 \mathrm{C} 1}+\mathrm{Res},
$$

where the subscripts CTL and $4 \mathrm{~K}$ denote the control simulation and the global warming simulation with free clouds, and $\mathrm{T} x \mathrm{C} x$ the simulations with locked clouds. The numbers indicate whether SST (denoted by T) and cloud-radiative properties (denoted by $\mathrm{C}$ ) are taken from the control simulation (denoted by 1 ) or from the global warming simulation (denoted by 2 ). The last term, Res, denotes the residual resulting from the application of the cloud-locking method. The residual is much smaller than the total response, implying that the cloud-locking method allows for a meaningful separation of SST and cloud-radiative impacts (Albern et al. 2019).

The contribution of global cloud-radiative changes to the total locked response is given by

$$
\Delta X_{\text {clouds }}=\frac{1}{2}\left[\left(X_{\mathrm{T} 1 \mathrm{C} 2}-X_{\mathrm{T} 1 \mathrm{C} 1}\right)+\left(X_{\mathrm{T} 2 \mathrm{C} 2}-X_{\mathrm{T} 2 \mathrm{C} 1}\right)\right] .
$$

We refer to this contribution as the global cloud impact. The SST impact is defined analogously and by design the difference between the total locked response and the global cloud impact. The SST impact was discussed in detail in Albern et al. (2019) and is shown in this study for reference.

To determine the impact of regional cloud-radiative changes, we perform additional simulations using the cloud-radiative properties from the control simulation and from the global warming simulation with a uniform SST increase. We investigate the impact of cloudradiative changes in the tropics $\left(30^{\circ} \mathrm{S}-30^{\circ} \mathrm{N}\right)$, in the midlatitudes $\left(30^{\circ}-60^{\circ} \mathrm{N}\right.$ and $\left.30^{\circ}-60^{\circ} \mathrm{S}\right)$, and in the polar regions (poleward of $60^{\circ} \mathrm{N} / \mathrm{S}$ ) (Fig. S1 in the online supplemental material).

To determine the impact of tropical cloud-radiative changes, we perform four simulations. In the first simulation, we prescribe the cloud-radiative properties in the tropics to the values from the global warming 
simulation and in the midlatitudes and polar regions to the values from the control simulation. In the second simulation, we prescribe cloud-radiative properties from the control simulation in the tropics, and from the global warming simulation in the midlatitudes and polar regions. These two simulations are once performed with SST from the control simulation and once with $+4 \mathrm{~K}$ SST. We run each simulation for 30 years and exclude the first year to avoid possible effects from model initialization. To determine the impact of cloud-radiative changes in the midlatitudes and polar regions, we perform two analogous sets of simulations (Fig. S1, center and right panels). To limit the number of required simulations, we change the cloud-radiative properties simultaneously in the Northern and Southern Hemisphere. For both the midlatitude and the polar cloud-radiative changes, we have tested that the circulation response in the Northern (Southern) Hemisphere is largely due to cloudradiative changes in the Northern (Southern) Hemisphere. Interhemispheric teleconnections occur (Ceppi et al. 2013), but they are small in our simulations (not shown).

Based on the above simulations, the impact of regional cloud-radiative changes is given by

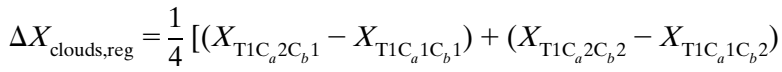

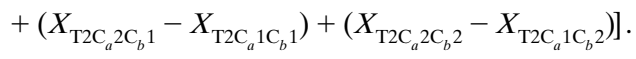

The subscript $a$ denotes the region for which the regional cloud-radiative impact is calculated (e.g., the tropics). The subscript $b$ refers to the other two regions (e.g., the midlatitudes and polar region). The cloud-radiative properties in the two regions of $b$ are prescribed to the same climate state. We refer to the three regional cloud impacts as the tropical cloud impact (cloud TR), the midlatitude cloud impact (cloud ML), and the polar cloud impact (cloud PO). In the following, we refer to the impact of cloud-radiative changes briefly as "cloud changes" and "cloud impacts."

By construction, the SST impact and the global cloud impact sum up to the total locked response. In contrast, the impacts from tropical, midlatitude, and polar cloud changes do not sum up to the global cloud impact, because Eq. (3) does not sample all possible combinations of cloud-radiative properties for the three regions. For example, the cloud-radiative properties in the two regions of $b$ are prescribed to the same climate state. Nevertheless, the sum of the tropical, midlatitude and polar cloud impacts on any variable exhibits a similar structure as the global cloud impact, and the magnitude of the difference is typically below $10 \%$. This is shown for the cloud impact on the global warming response of the zonal wind at $850 \mathrm{hPa}\left(u_{850}\right)$ in Fig. S2. This result is consistent with the finding of Butler et al. (2010) that the response to the sum of multiple thermal forcings is larger than the response to the simultaneously applied thermal forcings. In our simulations, the nonlinearity is additionally increased by possible gradients in the cloudradiative property fields at the borders of the three cloud regions.

\section{b. Regions of interest, circulation metrics, and statistical significance}

\section{1) REgIONS OF INTEREST}

We investigate the jet stream and its response to global warming at each longitude and in a zonal-mean perspective. For the zonal-mean perspective, we analyze both the zonal mean over all longitudes in the Northern and Southern Hemispheres and the zonal mean over the North Atlantic $\left(60^{\circ} \mathrm{W}-0^{\circ}\right)$ and North Pacific $\left(135^{\circ} \mathrm{E}-\right.$ $125^{\circ} \mathrm{W}$ ) ocean basins. The longitudinal boundaries of the ocean basins are taken from Barnes and Polvani (2013). Thus, our four regions of interest are the North Atlantic (NA), the North Pacific (NP), the Northern Hemisphere $(\mathrm{NH})$, and the Southern Hemisphere (SH).

\section{2) Circulation Metrics}

For comparability, we apply the same method to determine the latitude and strength of the midlatitude jet streams as previous studies (e.g., Barnes and Polvani 2013; Simpson et al. 2014; Albern et al. 2019). To this end, we interpolate the zonal wind at $850 \mathrm{hPa}\left(u_{850}\right)$ around its midlatitude maximum and the two neighboring grid points on a $0.01^{\circ}$ latitude grid and perform a quadratic fit (Barnes and Polvani 2013). The location and value of the maximum of the quadratic fit yield the jet latitude $\left(\varphi_{\text {jet }}\right)$ and the jet strength $\left(u_{\text {jet }}\right)$, respectively. We show both the zonal-mean jet (response) and the jet (response) at each longitude. For the former, the calculation of the jet is based on the zonal-mean $u_{850}$ for the respective region. The latter is based on $u_{850}$ at each longitude. As in Albern et al. (2019) we show latitudes for the Northern Hemisphere in "degrees north" and for the Southern Hemisphere in "degrees south," and a positive response in $\varphi_{\text {jet }}$ indicates a poleward jet shift in both hemispheres.

\section{3) Statistical SignificAnCE}

We use bootstrapping as a measure for significance, because the zonal wind data are not normally distributed and bootstrapping does not make assumptions about the distribution of the data. Statistical significance of the zonal wind and jet responses is calculated based on the 5th-95th-percentile range of the bootstrap distributions 
of the zonal wind and jet responses to global warming. The bootstrap distributions are determined in four steps: 1) for each simulation, we calculate the annual-mean or seasonal-mean time series of the zonal wind field at $850 \mathrm{hPa}$ for each of the 29 simulated years; 2) based on this time series, we perform a sampling with replacement (the resample has the same size as the original time series), and calculate the time mean over the resample; 3) the zonal-mean jet latitude and jet strength are determined from the zonal-mean of this time-mean $u_{850}$ field; and 4) the total zonal wind and jet responses and the global and regional cloud impacts are calculated as described in section $2 \mathrm{a}$. These four steps are performed 1000 times to obtain bootstrap distributions of the zonal wind and jet responses. We consider the zonal wind response to be significant if the 5th-95thpercentile range of the bootstrap distribution does not include $0 \mathrm{~m} \mathrm{~s}^{-1}$. The jet latitude and jet strength responses are significant if the 5 th-95th-percentile ranges of the bootstrap distributions do not include $0^{\circ}$ latitude and $0 \mathrm{~m} \mathrm{~s}^{-1}$, respectively. For the jet response, we also investigate the 1st-99th-percentile range of the bootstrap distributions to determine the spread in the response.

\section{Jet stream response to regional cloud-radiative changes}

In this section, we investigate the impact of tropical, midlatitude, and polar cloud changes on the zonal wind, jet stream, and storm track responses to global warming and determine which regional cloud impacts are most important for the global cloud impact. Albern et al. (2019) found that the global cloud impact is very similar across seasons. Here, we investigate whether this is also the case for the regional cloud impacts. Therefore, we focus our analysis on the annual-mean, December to February (DJF) and June to August (JJA) responses as these seasons span the range of large (DJF) and small (JJA) total jet responses. Note that in some regions, the JJA jet shift in ICON tends to be smaller than in other models (cf. Fig. S6 in Albern et al. 2019). We also investigated the March to May and September to November seasons and found similar results for the cloud impacts. Note that in all figures, the shown total response is always the total response for the simulations with locked clouds.

We begin with a brief summary of the main results of Albern et al. (2019), who studied the total response, the SST impact, and the global cloud impact. We include the results for the zonal mean over the Northern Hemisphere, which was not studied in Albern et al. (2019), and highlight the annual-mean, DJF, and JJA responses. Albern et al.
(2019) found that for most seasons and regions, the total $u_{850}$ response, the SST impact, and the global cloud impact exhibit dipole patterns around the jet latitude of the control simulation (cf. our Fig. 1). The dipole patterns indicate poleward jet shifts in the annual-mean and DJF in all regions, whereas the jets hardly shift in JJA, with the exception of modest poleward shifts of the North Atlantic and Northern Hemisphere jets. Further, the dipoles indicate a jet strengthening in the North Atlantic, Northern Hemisphere, and Southern Hemisphere during all seasons, while the North Pacific jet weakens in DJF and JJA. The global cloud impact supports the jet shift and jet strengthening in all regions that show a substantial total response.

The tropical, midlatitude, and polar cloud impacts also exhibit dipole patterns around the control jet latitude, especially in the annual mean and during DJF. This indicates that in principle all regional cloud changes can contribute to the $u_{850}$ and jet responses (Fig. 2). Yet, the tropical cloud impact clearly dominates the global cloud impact in the North Atlantic and Southern Hemisphere during all seasons (except for NA during DJF), and in the Northern Hemisphere and North Pacific during DJF. In the latter two regions, all regional cloud impacts are important in the annual mean and negligible in $\mathrm{JJA}$, which reflects the small total response during this season.

Moving from the zonal-mean perspective to the response at each longitude, we find that the global cloud impact is dominated by the tropical cloud impact (Fig. 3). The tropical cloud impact is significant in most regions in which the global cloud impact is significant. The midlatitude and polar cloud impacts are in general smaller and less significant. To first order, the impacts of regional cloud changes on the $u_{850}$ response are zonally symmetric in the midlatitude ocean basins, with the exception of the North Pacific during JJA. These results are in line with the finding of Albern et al. (2019) that the global cloud impact is largely zonally symmetric across the midlatitude ocean basins, whereas the SST increase causes a more zonally asymmetric $u_{850}$ response.

As an overview, Fig. 4 presents the relation between the zonal-mean poleward jet shift and jet strengthening in a scatterplot. This allows for immediate comparison with Albern et al. (2019). The statistical significance of the jet responses is shown in Figs. 5 and 6. Similar to the zonal wind response, the global cloud impact on the jet strength response is dominated by a significant tropical cloud impact (Figs. 4 and 5). The midlatitude and polar cloud changes hardly affect the jet strength response in any region and during any time of the year, and their small impacts are mostly not statistically significant. Note that in DJF, the total response of the North Pacific 

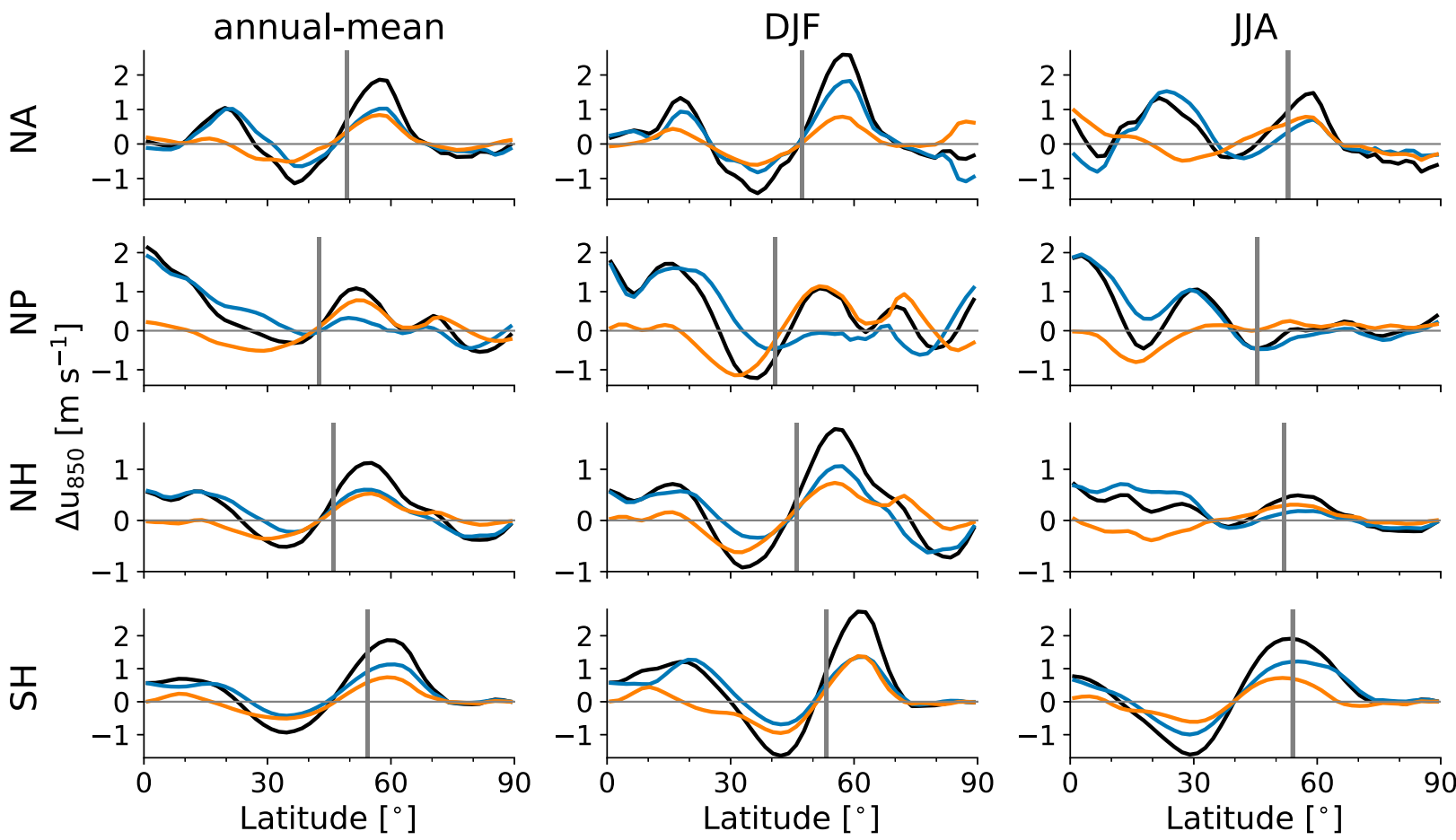

total SST cloud

FIG. 1. Zonal-mean response of the $850 \mathrm{hPa}$ zonal wind $\left(u_{850}\right)$ (left) in the annual mean and during (center) DJF and (right) JJA in the (top to bottom) North Atlantic (NA), North Pacific (NP), Northern Hemisphere (NH), and Southern Hemisphere (SH). The total response (black) is decomposed into the SST impact (blue) and the global cloud impact (orange). The gray bars show the jet latitude in the control simulation with locked clouds.

jet strength is not significant even though it is similar to the SST impact. This is because the variability in the total response is larger than for the SST impact. In general, the variabilities of the total $u_{\text {jet }}$ and $\varphi_{\text {jet }}$ responses and SST impacts are larger than the variabilities of the regional cloud impacts. This means that even though the regional cloud impacts are smaller in most cases, they are, at the same time, more robust than the total response and the SST impact (Figs. 5 and 6).

In contrast to the $u_{850}$ and $u_{\text {jet }}$ responses, all regional cloud changes contribute about equally to the annualmean and DJF $\varphi_{\text {jet }}$ response in the three Northern Hemisphere regions, except for the North Pacific in DJF, which is dominated by tropical cloud changes (Fig. 4). In the Southern Hemisphere, tropical and midlatitude cloud changes contribute to the annualmean and DJF poleward jet shift, whereas polar cloud changes tend to shift the jet equatorward. Most of the regional cloud impacts on $\Delta \varphi_{\text {jet }}$ are significant for the 1st-99th-percentile range (mainly cloud TR) or for the 5th-95th-percentile range (mainly cloud ML and cloud PO) (Fig. 6). In JJA, the total jet shift, the SST impact and all cloud impacts are small and mostly not significant (Figs. 4 and 6, bottom rows).

The jet shift in response to regional cloud changes in our simulations is in agreement with the jet response to regional cloud changes in aquaplanet simulations (Voigt and Shaw 2016). In both the aquaplanet setup and in the AMIP-like setup, tropical and midlatitude cloud changes contribute about equally to the poleward jet shift. This highlights the importance of tropical and midlatitude cloud-radiative heating for the poleward jet shift (cf. section 4). At the same time, the role of polar cloud changes is more uncertain and seems to be model dependent. In one of the aquaplanet models of Voigt and Shaw (2016) the polar cloud impact was about half of the tropical and midlatitude cloud impacts whereas it was negligible in the other model. In our simulations, the polar cloud impact on the jet shift is more important and contributes in some circumstances as much to the poleward jet shift as the tropical and midlatitude cloud impacts (cf. Fig. 4; e.g., the DJF jet shift in the North Atlantic).

Considering the differences in the model setups of the aquaplanet and the AMIP-like simulations, it is 

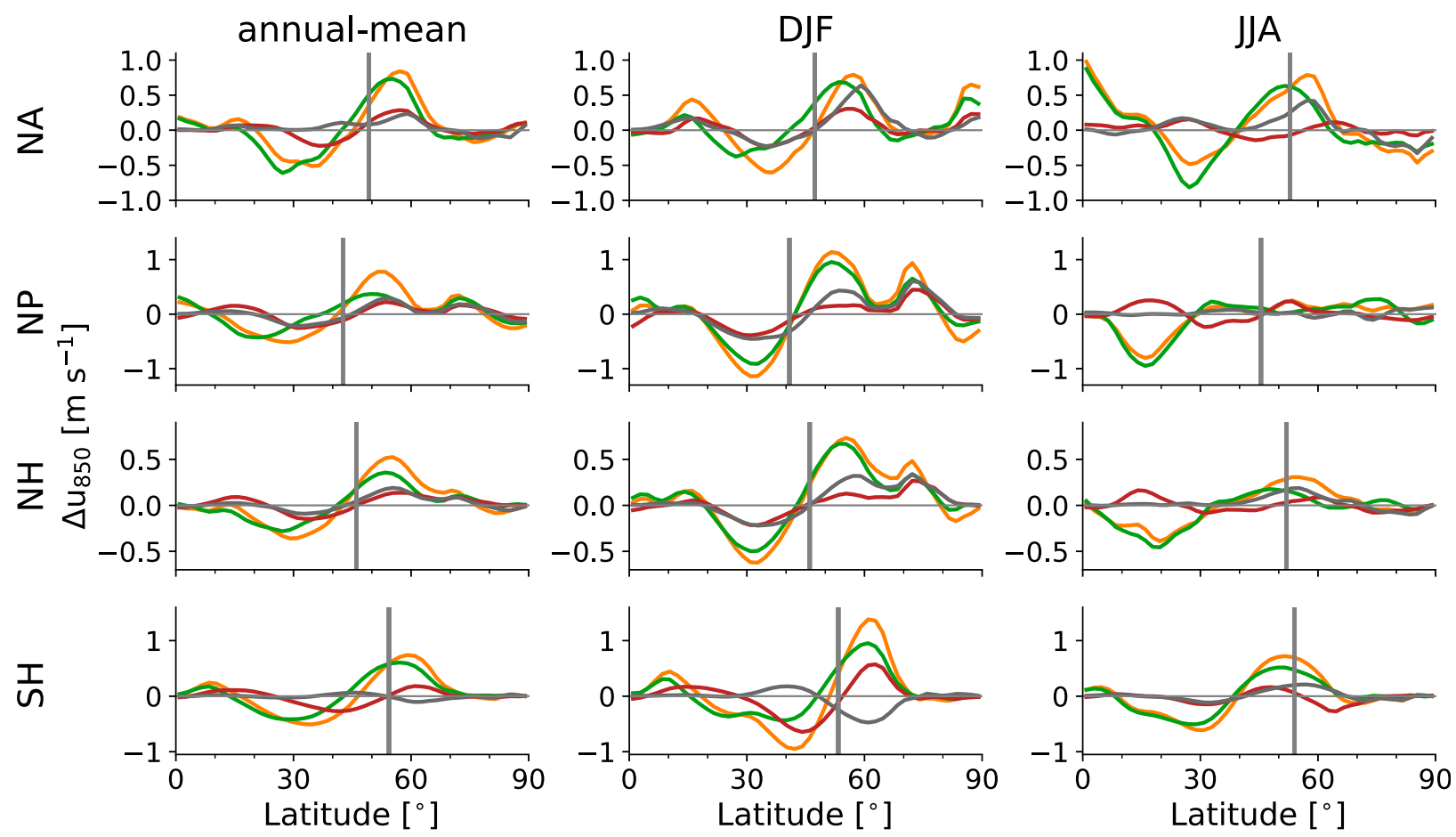

cloud cloud TR cloud ML cloud PO

FIG. 2. Zonal-mean response of the $850 \mathrm{hPa}$ zonal wind $\left(u_{850}\right)$ (left) in the annual mean and during (center) DJF and (right) JJA in the (top to bottom) North Atlantic (NA), North Pacific (NP), Northern Hemisphere (NH), and Southern Hemisphere (SH). Shown are the global (orange), tropical (cloud TR; green), midlatitude (cloud ML; brown), and polar (cloud PO; gray) cloud impacts. The gray bars show the jet latitude in the control simulation with locked clouds.

surprising how well the results agree. As the cloud impacts are similar across seasons, the aquaplanet (without a seasonal cycle) is a useful tool to study the role of (regional) cloud changes. Differences between the AMIP-like and aquaplanet simulations might be related to the inclusion of sea ice and continents in our simulations, which was found to be important for the jet (Brayshaw et al. 2009) and the cloud impact in different ocean basins (Albern et al. 2019). Additionally, Voigt and Shaw (2016) prescribe water vapor to values from the control simulation in the global warming simulation, whereas water vapor is free in our simulations. Finally, Voigt and Shaw (2016) do not calculate the mean over four simulations to derive the cloud impact [Eq. (3)], but

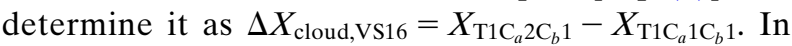
our simulations, this calculation results in a highly overestimated global cloud impact on the jet response, whereas the three regional cloud impacts in the aquaplanet simulations almost sum up to the global cloud impact.

The jet streams are tightly coupled to the storm tracks, which are a measure of synoptic activity in the midlatitudes (e.g., Hoskins and Valdes 1990; Pinto et al. 2007). The storm tracks are derived as the standard deviation of the 2.5-6-day bandpass filtered 6-hourly geopotential height at $500 \mathrm{hPa}$ (Blackmon 1976). Depending on the ocean basin and season, the storm tracks shift poleward and strengthen in response to global warming (Fig. 7, first row). The global cloud impact contributes significantly to the total response in all ocean basins in the annual mean and to the North Atlantic response in JJA (Fig. 7, second row) (statistical significance of the storm track response is determined analogously to the $u_{850}$ response). Similar to the $u_{850}$ response, the global cloud impact on the storm track response is dominated by tropical cloud changes, whose impact is significant in large parts of the ocean basins and across seasons, even in regions where the global cloud impact is not significant (Fig. 7, third row). The midlatitude and polar cloud impacts also contribute to the global cloud impact but are weaker and less significant (Fig. 7, fourth and fifth rows). Significant impacts of midlatitude and polar cloud changes are mainly found in the North Atlantic and at the equatorward flank of the North Pacific and Southern Hemisphere storm tracks. 

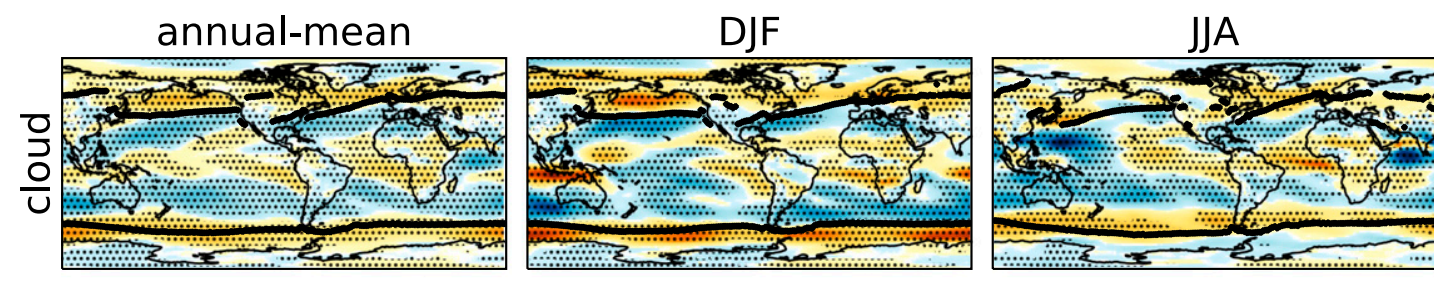

$-2$
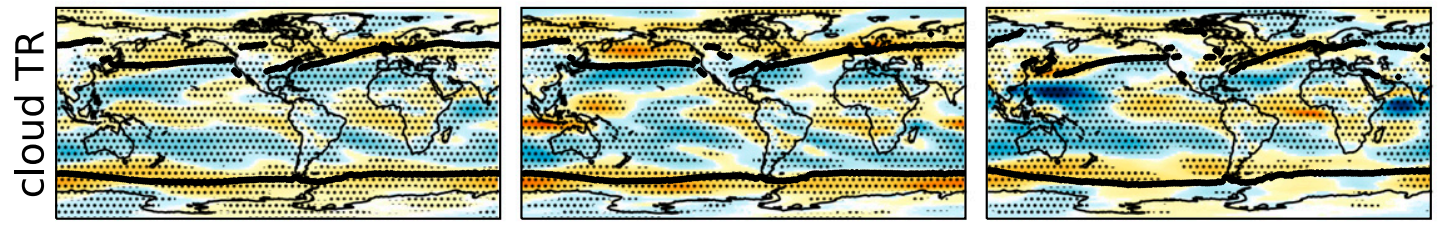

1
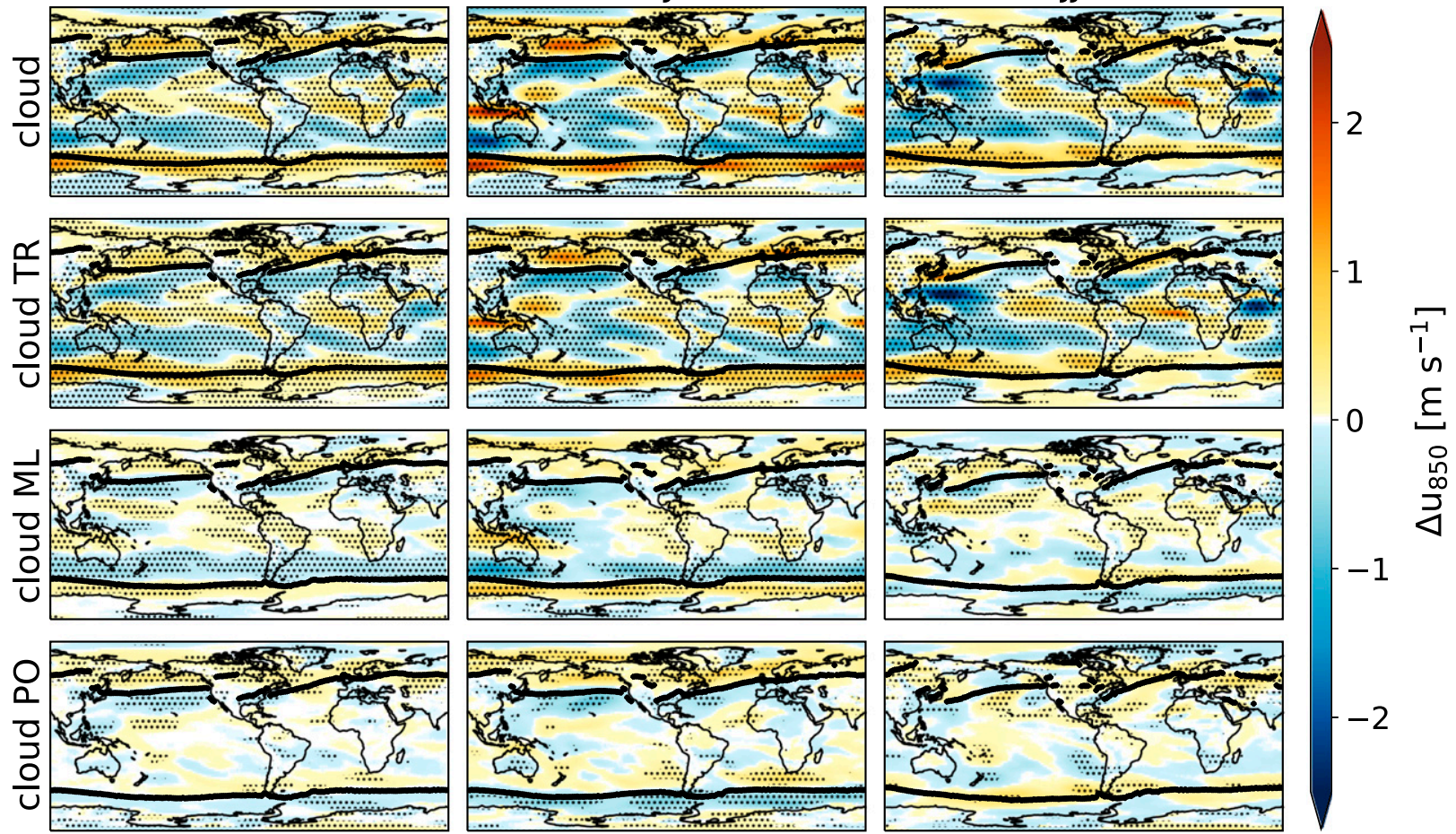

$-1$

$-2$

FIG. 3. (left) Annual-mean, (center) DJF, and (right) JJA response of the zonal wind at $850 \mathrm{hPa}\left(u_{850}\right)$ to global warming. Depicted are the (top to bottom) global (cloud), tropical (cloud TR), midlatitude (cloud ML), and polar (cloud PO) cloud impacts. The dots indicate where the response is statistically significant based on the 5th-95th-percentile range of the bootstrap distribution for each grid point. The black line indicates the jet latitude in the control simulation with locked clouds.

\section{Dynamical processes-Changes in baroclinicity and eddies}

In this section, we explore the dynamics behind the zonal wind and jet stream responses to cloud-radiative changes. As summarized in the previous section, there are two primary and robust linkages between regional changes in cloud-radiative heating and responses in the extratropical circulation: 1) changes in tropical cloudradiative heating dominate changes in the strength of the jets, and 2) changes in both tropical and midlatitude cloud-radiative heating contribute to the poleward jet shifts. There are interesting and important seasonal differences in the jet responses, but these are due as much to the SST increase as to changes in cloudradiative properties (Figs. 5 and 6). The fact that the jets hardly shift in JJA indicates that the background climate state on which the cloud-radiative heating and SST increase are imposed is important for the jet shift. The dominating processes, however, are still unclear and an area of active research. For this reason, here we focus on the annual-mean jet shift and investigate the qualitative relationships between changes in cloud-radiative heating and various dynamical properties of the extratropical atmosphere. We begin with the changes in atmospheric cloud-radiative heating since they are the forcing whereby changes in clouds influence the circulation.

The contours in Fig. 8 show the changes in zonal-mean atmospheric cloud-radiative heating for the global and regional cloud impacts. The changes in cloud-radiative heating are all dominated by their longwave components (not shown). The shading in Fig. 8 shows the corresponding responses in zonal-mean atmospheric temperature. Note that the responses in temperature are due not only to the imposed cloud-radiative heating, but also to the resulting changes in atmospheric dynamical and diabatic processes.

The qualitative structure of changes in upper-level cloud-radiative heating (Fig. 8, top) is consistent with the response of high-level clouds to global warming (e.g., Manabe and Wetherald 1987) and can be understood primarily from 1) the lifting of the tropopause across all latitudes in response to global warming (Hartmann and Larson 2002; Singh and O'Gorman 2012; Thompson et al. 2017); 2) the poleward shift of the extratropical storm tracks and their associated cloud fields (e.g., Kushner et al. 2001); and 3) the fact that high-level clouds warm at their base and cool at 
NA
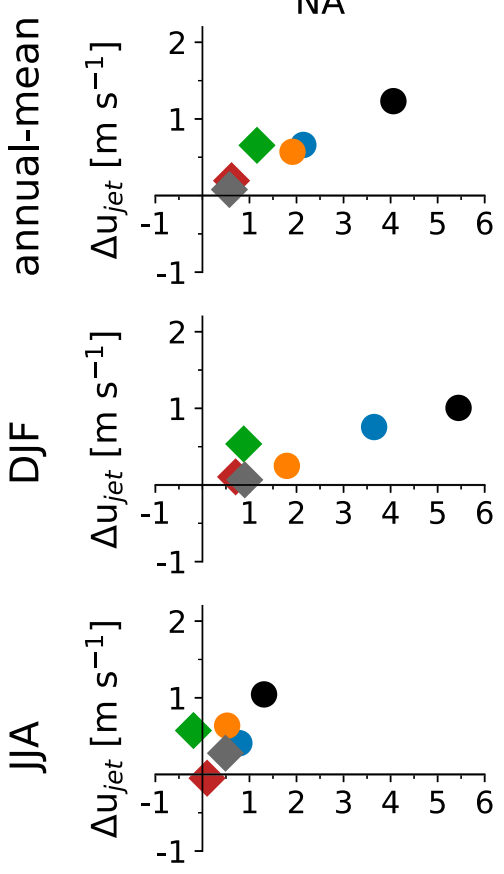

$\Delta \varphi_{\text {jet }}\left[{ }^{\circ}\right]$
NP
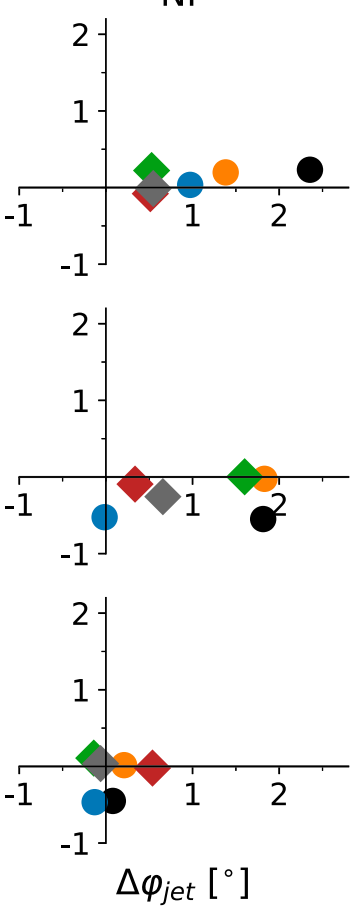
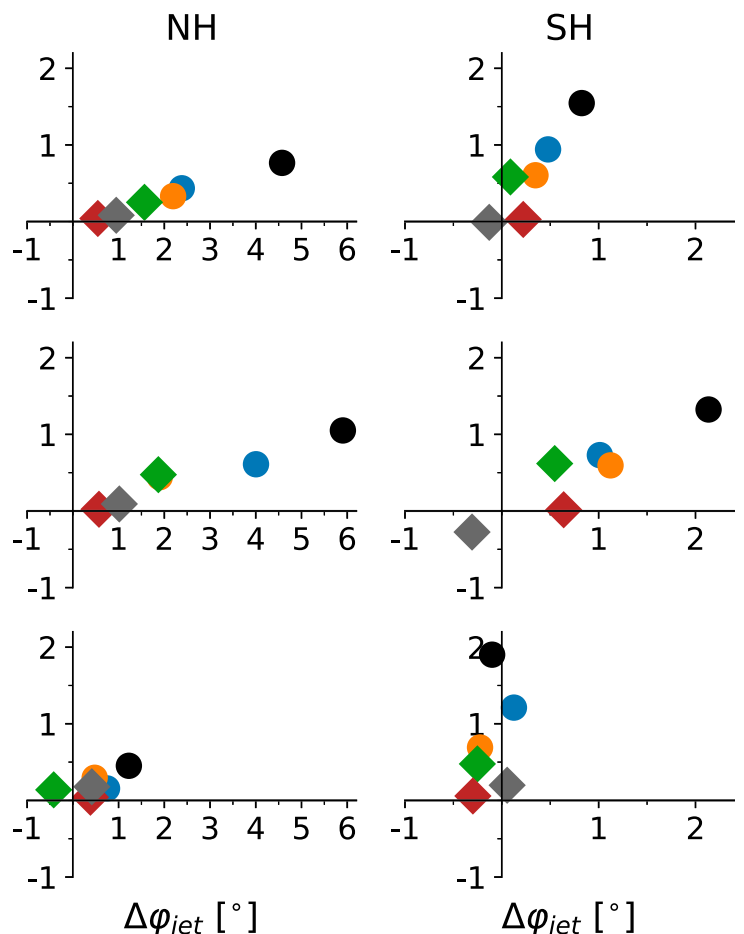

total

SST

cloud TR

cloud ML

cloud PO

FIG. 4. Zonal-mean jet shift $\Delta \varphi_{\text {jet }}$ vs jet strengthening $\Delta u_{\text {jet }}$ (top) in the annual mean and during (middle) DJF and (bottom) JJA. Shown are the total response (black), the SST impact (blue), and the global (orange), tropical (cloud TR; green), midlatitude (cloud ML; brown), and polar (cloud PO; gray) cloud impacts for the (left to right) North Atlantic (NA), North Pacific (NP), Northern Hemisphere (NH), and Southern Hemisphere (SH).

their top (Slingo and Slingo 1988). The changes in lower-level cloud-radiative heating reflect a reduction in subtropical low-level clouds and an upward extension of exratropical low-level clouds, whose radiative effect in the present-day climate is dominated by cooling (Li et al. 2015).

The bowed structure of the cloud-radiative heating change in the upper troposphere reflects the meridional structure of the tropopause and is robust in climate change simulations in aquaplanet setups (Voigt and Shaw 2016), AMIP-like simulations (Li et al. 2019; Albern et al. 2019) and simulations with interactive sea surface temperatures (Ceppi and Shepherd 2017; Voigt et al. 2019). Yet, the magnitude of the change in cloudradiative heating differs across models, which to a large extent is due to model shortcomings regarding the cloudradiative heating in the present-day climate (Voigt et al. 2019). At the same time, the response in the lowertropospheric polar region is uncertain across models, even when the lower-tropospheric response is limited due to prescribed sea surface temperatures and sea ice. For the most part, the changes in cloud-radiative heating and the resulting temperature response are much larger for the tropical cloud impact than they are for the extratropical cloud impacts (e.g., compare the lower three panels in Fig. 8). Nevertheless, as indicated in the previous section, the changes in extratropical clouds appear to play an important role for the jet response. For the midlatitude cloud changes, this is likely because the cloud-radiative heating occurs right at the jet latitude and its poleward flank and modifies the baroclinicity in this region (see discussion below).

How do the changes in cloud-radiative heating influence the midlatitude circulation from a dynamical perspective? It is helpful to split the task of understanding how changes in cloud-radiative heating lead to the jet shifts into three parts. The first part corresponds to the direct, linear (dry) atmospheric response that follows from the imposed change in external heating. The second part includes understanding the resulting response in the (dry) eddy transports of heat and momentum that result from the linear response. The third part includes moist processes such as convection. The first part is relatively straightforward, but the second part is nonlinear and more difficult to quantify. In fact, understanding the eddy response to external heating lies at the 

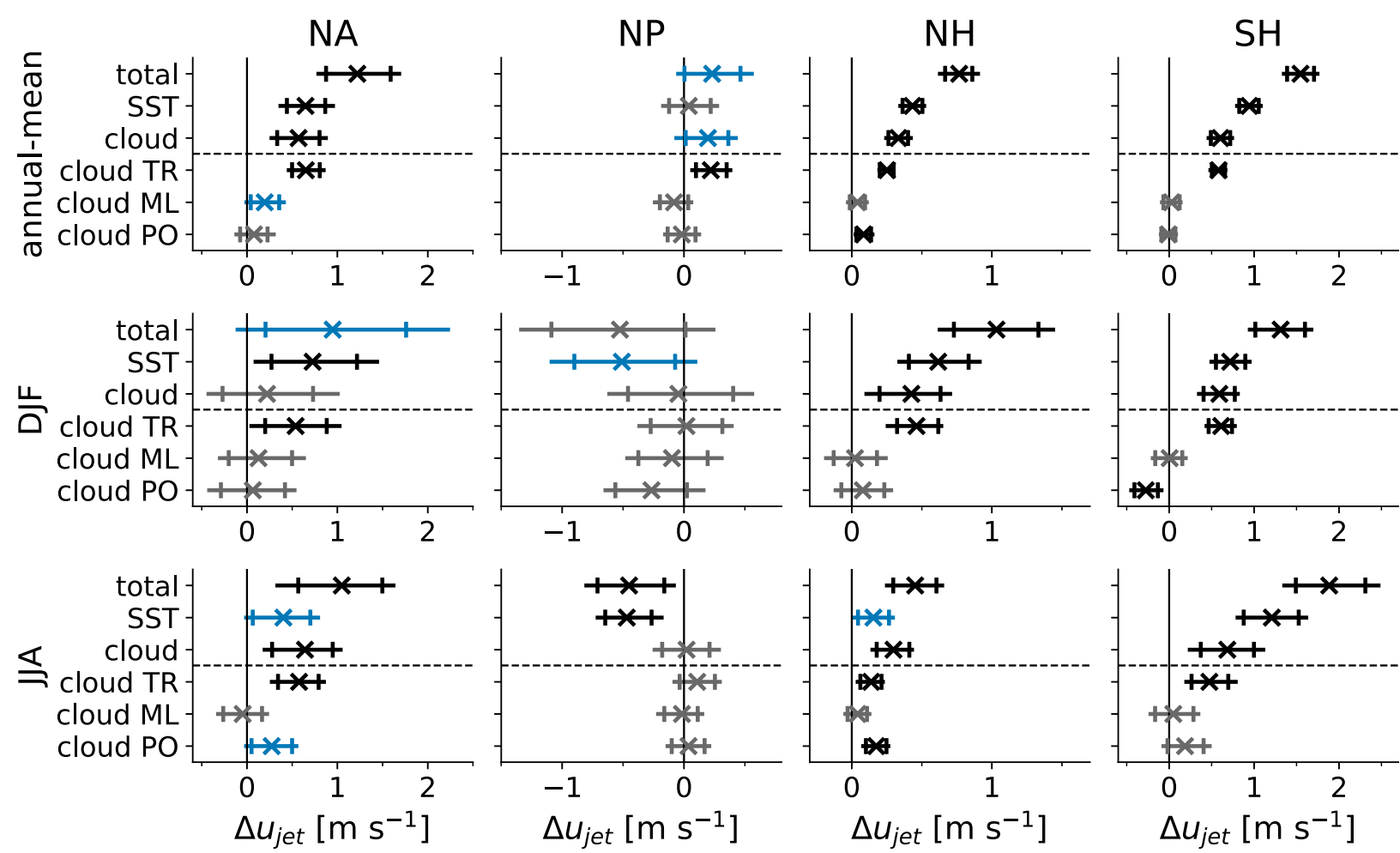

1st-99th percentile significant 5th-95th percentile significant not significant

FIG. 5. The 1st-99th-percentile range (horizontal lines), median (crosses), and 5th and 95th percentiles (vertical lines) of bootstrap distributions of the zonal-mean jet strength response $\left(\Delta u_{\text {jet }}\right)$. Results are shown for (top) the annual mean, (middle) DJF, and (bottom) JJA, and for the (left to right) North Atlantic (NA), North Pacific (NP), Northern Hemisphere (NH), and Southern Hemisphere (SH). Shown are the total response, the SST impact, and the global and regional cloud impacts. The colors indicate whether the response is significant based on the 1st-99th-percentile range or the 5th-95th-percentile range or whether the response is not significant.

root of understanding the circulation response to climate change, to the ozone hole, to stratospheric dynamical processes, and to sea surface temperature anomalies. It is a key and topical problem in climate dynamics. Regarding the third part, Voigt and Shaw (2016) found a 3-times-larger jet shift in the dry version of one of their aquaplanet models than they did in the moist full-physics version of the model. This indicated an important role of small-scale processes in compensating for some of the cloud-radiative heating, in particular due to convection and boundary layer mixing. In this section, we will focus on the second part, because the first part is relatively straightforward and the third part requires running a model, since there is no theoretical framework that predicts the response of small-scale processes to cloud-radiative heating changes.

The eddy response to external heating arises through a combination of two processes. These are 1) barotropic processes, in which changes in the configuration of the free-tropospheric flow influence the meridional propagation of waves (Hoskins and Karoly 1981; Chen and Held 2007; Simpson et al. 2009; Barnes et al. 2010; Barnes and
Thompson 2014); and 2) baroclinic processes, in which changes in the baroclinicity lead to changes in the eddy fluxes of heat (Lindzen and Farrell 1980; Kushner and Held 1998; O'Gorman 2010; Butler et al. 2011) andthrough the resulting changes in the "stirring" of the flow-changes in the meridional flux of wave activity and thus momentum fluxes aloft (e.g., Dickinson 1969; Held 1975).

For the specific case of the midlatitude response to cloud-radiative heating changes: Previous work has argued that the pattern of cloud-radiative heating in the upper troposphere that results from global warming (e.g., similar to that shown in Fig. 8, top) leads to a poleward shift of the midlatitude jet (e.g., Voigt and Shaw 2016; Albern et al. 2019; Li et al. 2019; Voigt et al. 2019). In fact, a pattern of cloud-radiative heating very similar to that found in Fig. 8 leads to a poleward shift in the midlatitude jets when applied to the dynamical core of a global climate model ( $\mathrm{Li}$ et al. 2019). In that case, the influence of the heating on upper-tropospheric baroclinicity appears to play a key role in driving responses in the amplitudes of baroclinic eddies and thus the 

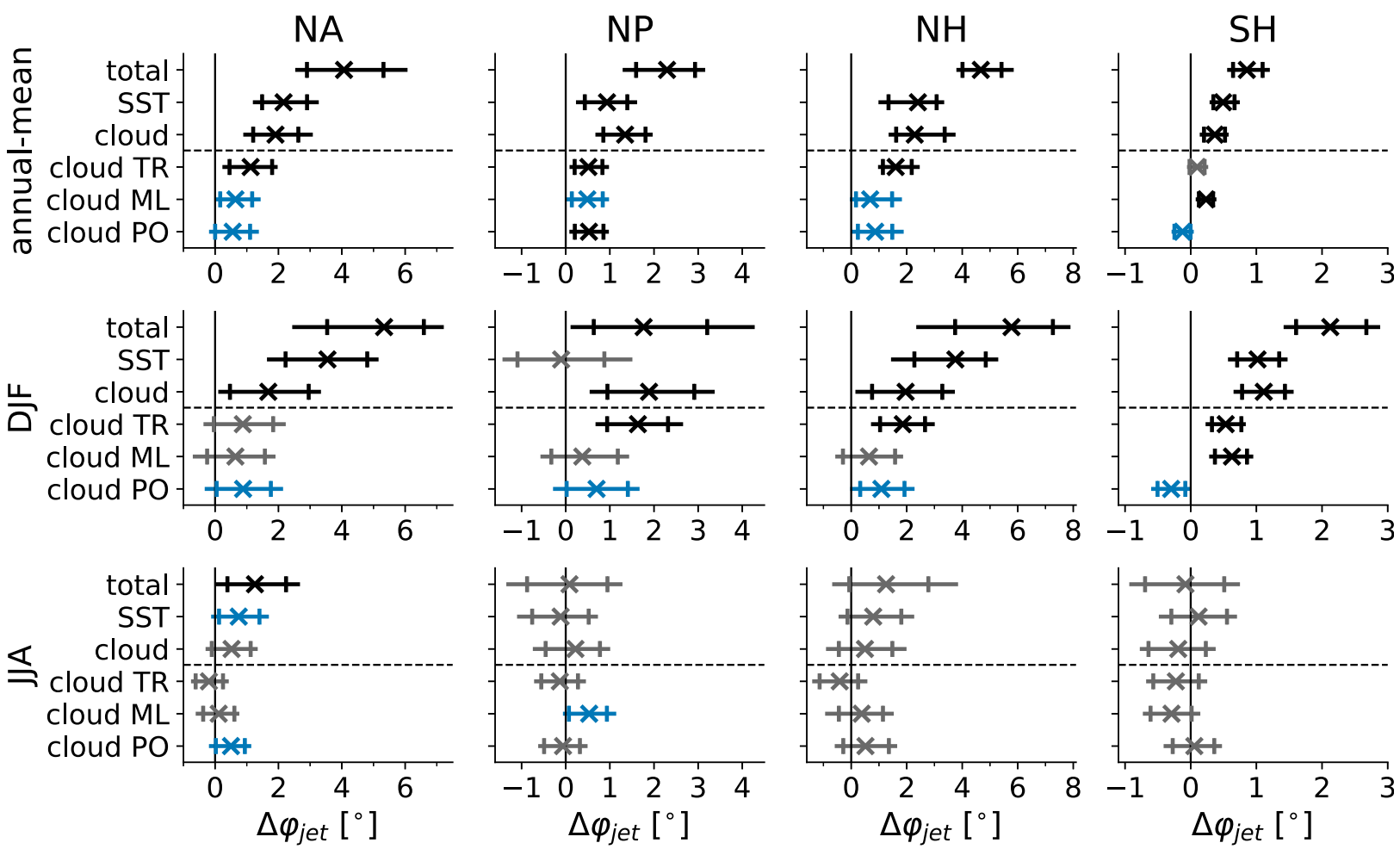

1st-99th percentile significant 5th-95th percentile significant

not significant

FIG. 6. As in Fig. 5, but for jet latitude response $\left(\Delta \varphi_{\text {jet }}\right)$.

extratropical wave fluxes of heat. Figures 9 and 10 suggest that a similar process is important for understanding at least a component of the results shown here. Note that in contrast to earlier figures, the results are shown as a function of logarithmic pressure to emphasize relationships in the upper troposphere. The eddy fluxes of heat and momentum are calculated based on 6-hourly data following Peixoto and Oort (1992). The meridional temperature gradient and eddy momentum flux convergence are calculated as

$$
\frac{1}{a} \frac{\partial \bar{T}}{\partial \varphi} \quad \text { and } \quad-\frac{1}{a \cos ^{2} \varphi} \frac{\partial\left(\overline{u^{\prime} v^{\prime}} \cos ^{2} \varphi\right)}{\partial \varphi},
$$

respectively. Here, the overbar $\overline{(\cdot)}$ denotes the time mean and zonal mean, the prime $(\cdot)^{\prime}$ is the eddy component (i.e., the deviation from the time mean or zonal mean), $a=6371 \mathrm{~km}$ is Earth's radius, $T$ is the atmospheric temperature, $u^{\prime} v^{\prime}$ is the eddy momentum flux, and $\varphi$ is the latitude.

The left column in Fig. 9 shows the response in the zonal-mean temperature (shading; reproduced from Fig. 8) along with the attendant response in the meridional temperature gradients (contours) for all cloud impacts. Note that the response in the meridional temperature gradients dominate the total changes in the baroclinicity and thus the Eady growth rate (Fig. S3). As expected, the largest response in the meridional temperature gradient are found on the poleward flanks of the tropical upper-tropospheric temperature increases (about $40^{\circ}-50^{\circ} \mathrm{N} / \mathrm{S}$ ) (Fig. 9, left column) and are dominated by tropical cloud changes, which yield the largest temperature response of all three regions due to enhanced tropical heating (Fig. 9, left column, shading). The response in the meridional temperature gradients associated with midlatitude and polar cloud changes are relatively modest. Note that the largest meridional temperature gradient and eddy heat flux responses are found in the upper troposphere, even though the largest values in the control simulation are found in the lower troposphere around $800-900 \mathrm{hPa}$.

If the changes in cloud-radiative heating directly influence the eddy fluxes of heat, then we would expect to see three relationships hold in the results: 1) the response in the eddy fluxes of heat should be downgradient (i.e., diffusive) with respect to the response in atmospheric temperatures; 2 ) the response in the eddy fluxes should be dominated by their transient rather than stationary components, since the transient component is most closely associated with baroclinic eddies; and 3) the 

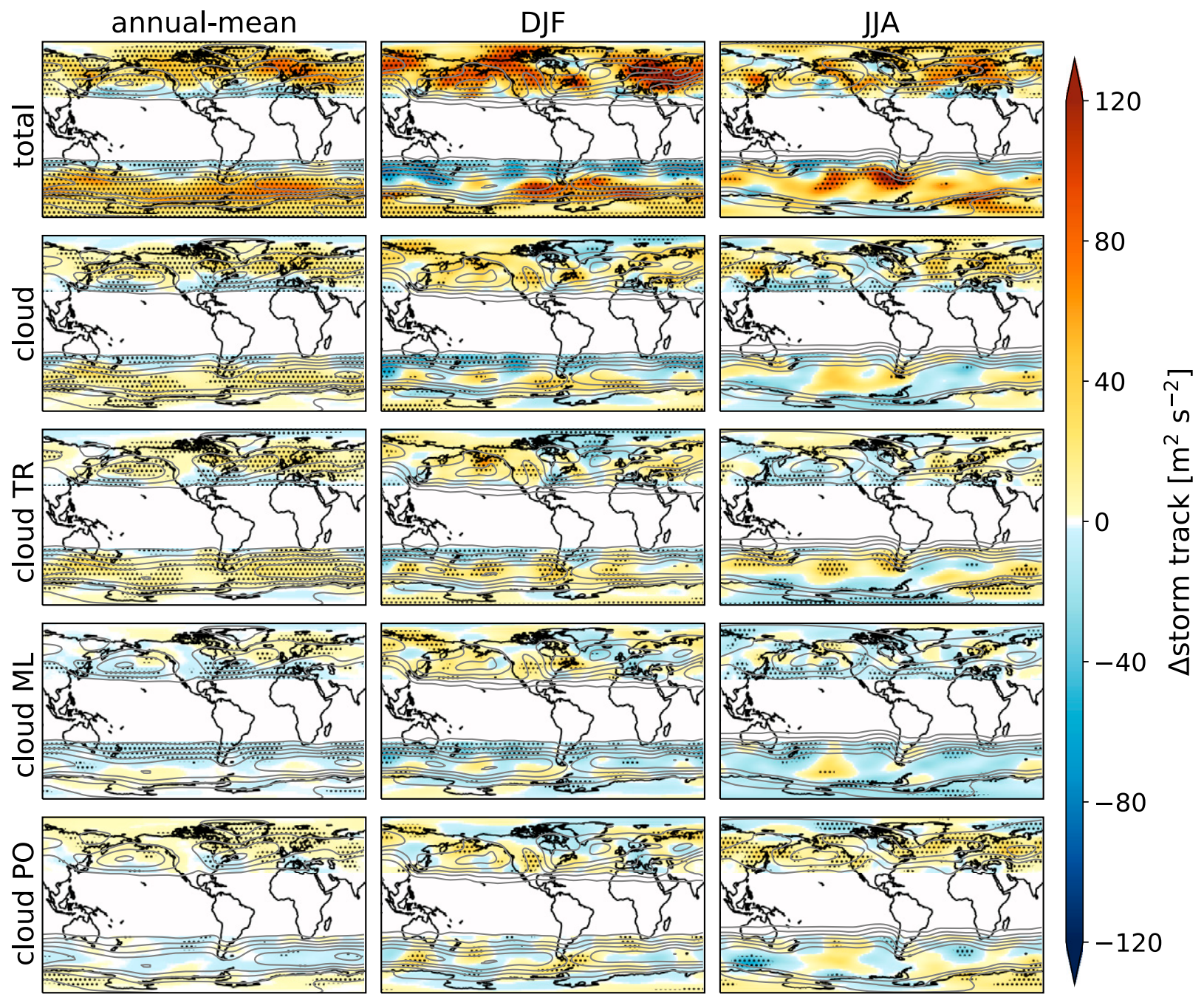

$-120$

FIG. 7. (left) Annual-mean, (center) DJF, and (right) JJA storm track response to global warming. Depicted are the (top to bottom) total response and the global (cloud), tropical (cloud TR), midlatitude (cloud ML), and polar (cloud PO) cloud impacts. The dots indicate regions with a statistically significant response based on the 5th-95th-percentile range of the bootstrap distribution. The gray contours show the storm track in the control simulation (contour interval: $100 \mathrm{~m}^{2} \mathrm{~s}^{-2}$ ). The tropics are not shown because the storm track is weak in this region.

response in the eddy fluxes should be most clearly diffusive at upper tropospheric levels, where the temperature response is forced directly by the changes in the cloud-radiative heating and not solely by the resulting changes in atmospheric dynamics. Though not perfect, all three relationships are evident in the model responses (Fig. 9, second and third columns): The changes in the transient eddy fluxes of heat are largely downgradient in the upper troposphere. The diffusive nature of the heat fluxes is most clear in association with the tropical cloud impact, but is also apparent for the midlatitude and polar cloud impacts.

To the extent that most baroclinic eddies do not extend into the lower stratosphere, increases in the transient eddy fluxes of heat in the upper troposphere should lead to increases in the so-called stirring of the upper-tropospheric flow. Increases in the amplitude of the stirring should, in turn, lead to increases in the meridional propagation of Rossby waves and thus the convergence of the eddy momentum flux.

The first two columns of Fig. 10 show the responses in the transient eddy momentum flux convergence (shading; first column) and stationary eddy momentum flux convergence (shading; second column) overlaid with the responses in the meridional temperature gradients (contours). The third column shows the total responses in the eddy momentum flux convergence (stationary plus transient component; shading) overlaid with the 


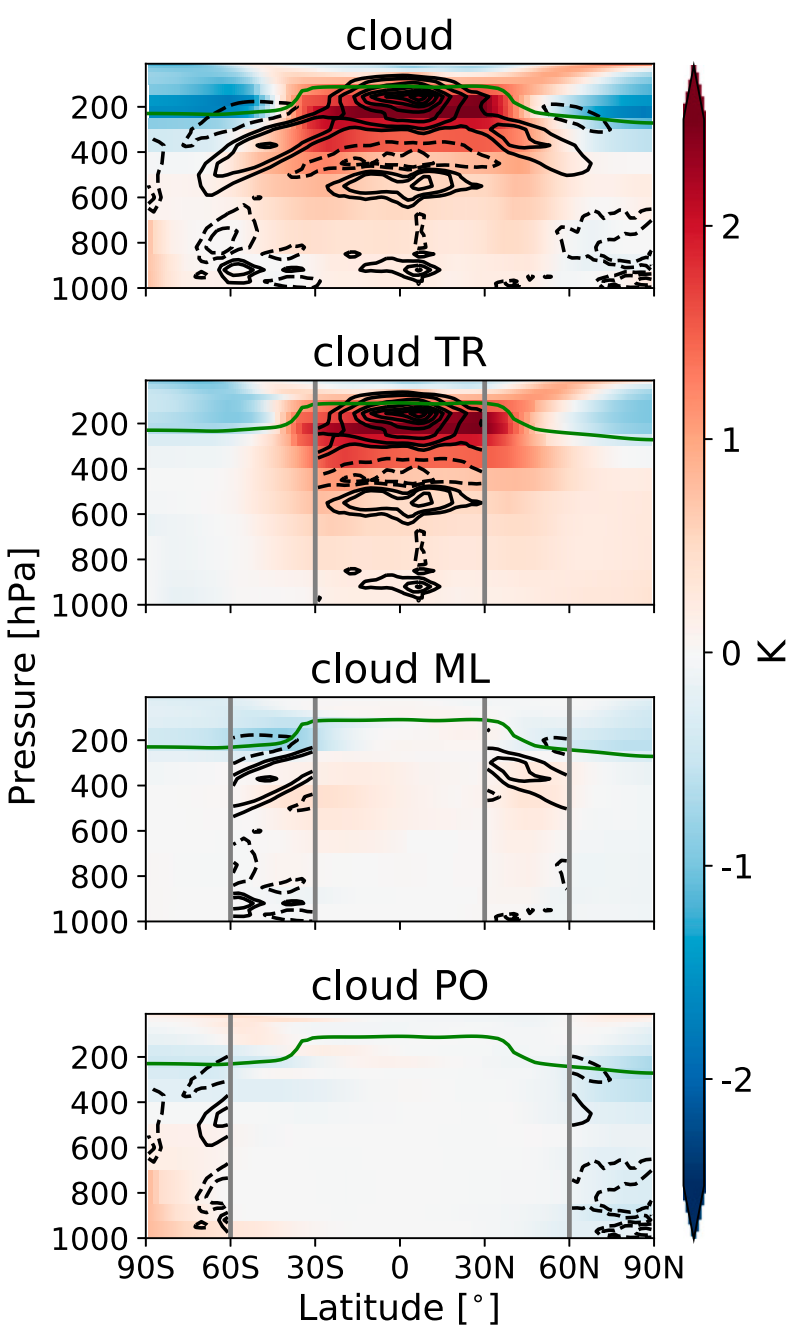

FIG. 8. Annual-mean global and regional cloud impacts on the temperature response (shading) vs change in atmospheric cloudradiative heating (contours). The gray bars indicate the latitudinal boundaries of the tropical, midlatitude, and polar regions. The contour interval is $0.2 \mathrm{~K} \mathrm{day}^{-1}$ for absolute values larger than $0.2 \mathrm{~K} \mathrm{day}^{-1}$ and $0.1 \mathrm{~K} \mathrm{day}^{-1}$ for absolute values smaller than $0.2 \mathrm{~K} \mathrm{day}^{-1}$. The $0 \mathrm{~K} \mathrm{day}^{-1}$ contour is not shown. The green lines show the tropopause height in the control simulation.

responses in the zonal-mean zonal wind. Consistent with our hypothesis, the largest responses in the transient eddy momentum flux convergence lie within-albeit on the poleward side of-the largest responses in the meridional temperature gradient (Fig. 10, left column). The relationships are most clear for the global and tropical cloud impacts. Interestingly, the midlatitude and polar cloud impacts are marked by more substantial responses in the stationary eddy momentum fluxes in the Northern Hemisphere, which is consistent with the results of Simpson et al. (2014), who found that the stationary component of the eddy momentum flux is apparently important in simulations with continents, especially in the Northern Hemisphere during DJF. The responses in the stationary eddy fluxes are important, but they are not clearly linked to changes in tropospheric baroclinicity and the responses are more difficult to interpret physically. The zonal wind response is-as expectedconsistent with the response of the eddy momentum fluxes (Fig. 10, right column), and the responses in the surface flow follow from the attendant responses in the vertically integrated momentum transport (Vallis 2017). Yet, the results indicate that the linkages between baroclinicity and transient eddies are not the complete story in the Northern Hemisphere, and that the stationary component of the eddy momentum flux cannot be neglected in simulations with continents and a seasonal cycle. The stationary component of the eddy momentum flux is important for regional cloud impacts outside of the tropics.

Together the results in Figs. 8-10 suggest that the jet responses to cloud-radiative changes are at least qualitatively consistent with the following reasoning: 1) cloud-radiative changes influence upper-tropospheric baroclinicity and thus the available potential energy for wave motions; 2 ) the changes in baroclinicity lead to anomalous downgradient wave fluxes of heat associated with transient waves; 3) the changes in the transient wave fluxes of heat and thus the vertical propagation of wave activity lead to changes in the so-called stirring of the upper-tropospheric flow; and 4) the changes in stirring lead to changes in the meridional flux of wave activity and thus eddy momentum fluxes aloft. Whether the cloud-radiative heating change leads to a shift or strengthening of the jet presumably depends on whether the changes in upper-tropospheric baroclinicity project onto the climatological-mean jet or its poleward flank.

\section{Conclusions}

We investigate the impact of regional cloud-radiative changes on the annual-mean, DJF, and JJA jet stream responses to a uniform $4 \mathrm{~K} \mathrm{SST}$ increase across regions, using the atmospheric component of the ICON model. We apply the cloud-locking method, and isolate the atmospheric pathway of the cloud impact by prescribing SST (Voigt et al. 2019). We summarize the main findings of this study by answering the research questions that we posed in the introduction:

1) Are tropical, midlatitude or polar cloud-radiative changes more important for the global cloud impact on the zonal wind, jet stream, and storm track responses to global warming? Do the results depend on the season and the region? 

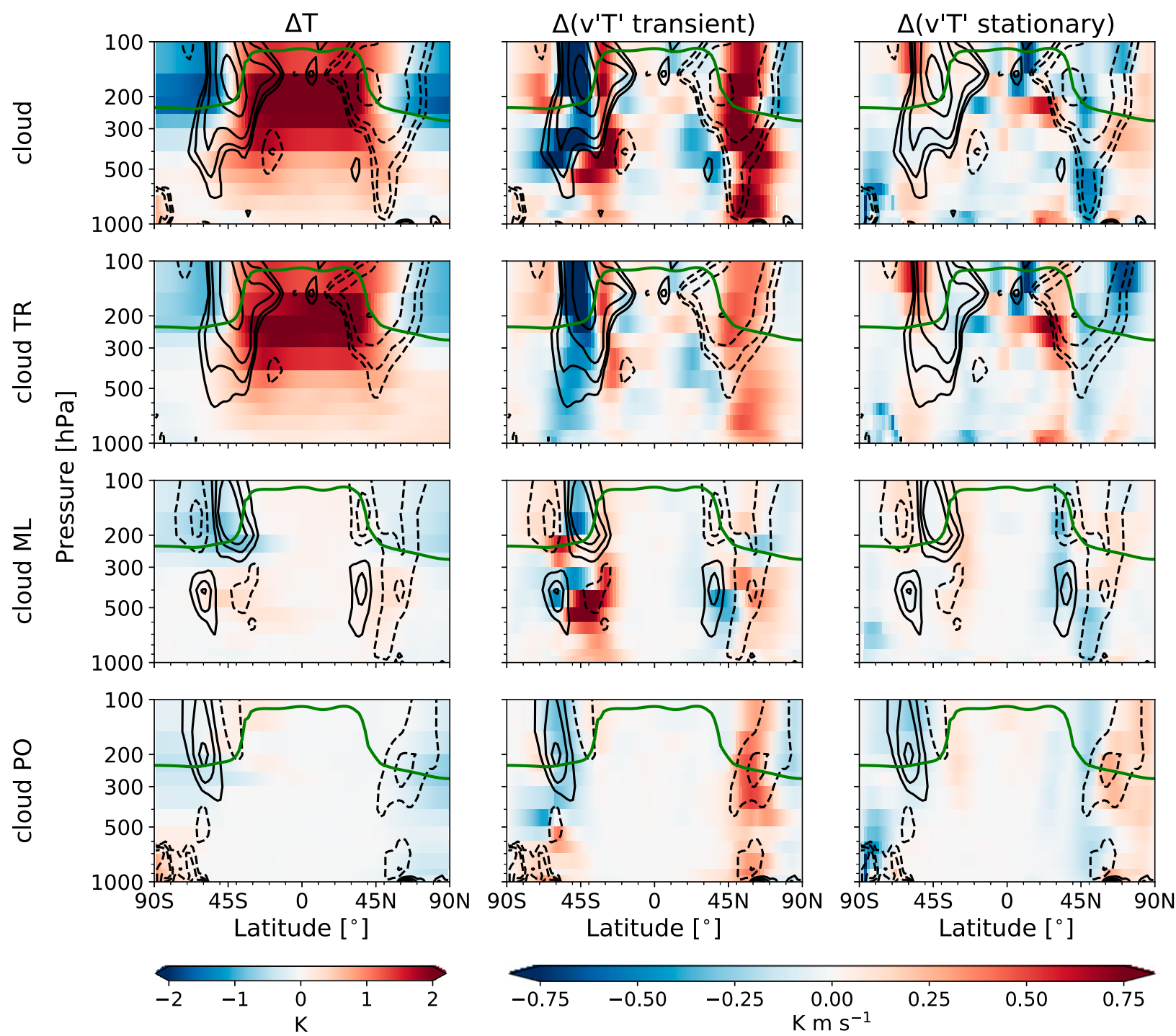

FIG. 9. Cloud impacts on the response of the annual-mean zonal-mean (left) atmospheric temperature, (middle) transient eddy heat flux, and (right) stationary eddy heat flux (shading), overlaid by responses in the meridional temperature gradient (contours). The contours are in intervals of $0.5 \mathrm{~K}\left(10^{3} \mathrm{~km}\right)^{-1}$ between -4 and $-0.5 \mathrm{~K}\left(10^{3} \mathrm{~km}\right)^{-1}$ and between 0.5 and $4 \mathrm{~K}\left(10^{3} \mathrm{~km}\right)^{-1}$, with additional contours for \pm 0.3 and $\pm 0.2 \mathrm{~K}\left(10^{3} \mathrm{~km}\right)^{-1}$ for the global and tropical cloud impacts, and $\pm 0.3, \pm 0.2$, and $\pm 0.1 \mathrm{~K}\left(10^{3} \mathrm{~km}\right)^{-1}$ for the midlatitude and polar cloud impacts. The green lines show the tropopause height in the control simulation.

The global cloud impacts on the $850 \mathrm{hPa}$ zonal wind, jet strength, and storm track responses are dominated by significant tropical cloud impacts across seasons, especially in the North Atlantic and Southern Hemisphere. The regional cloud impacts on the zonal wind response are largely zonally symmetric. The tropical and midlatitude cloud impacts contribute substantially to the annual-mean and DJF poleward jet shifts in most regions. The polar cloud impact contributes to the poleward jet shifts in the three northern hemispheric regions, but shifts the Southern Hemisphere jet equatorward. Thus, while in principle all clouds can contribute to the zonal wind, jet stream, and storm track responses, our study highlights the importance of tropical cloud changes.

2) Can we understand the impact of regional cloudradiative changes on the zonal wind and jet responses based on (established) dynamical arguments?

While the temperature response to cloud-radiative heating is difficult to understand, the zonal wind response to cloud-induced temperature changes can be understood from dry dynamics and previous work with idealized dry models. The circulation changes 

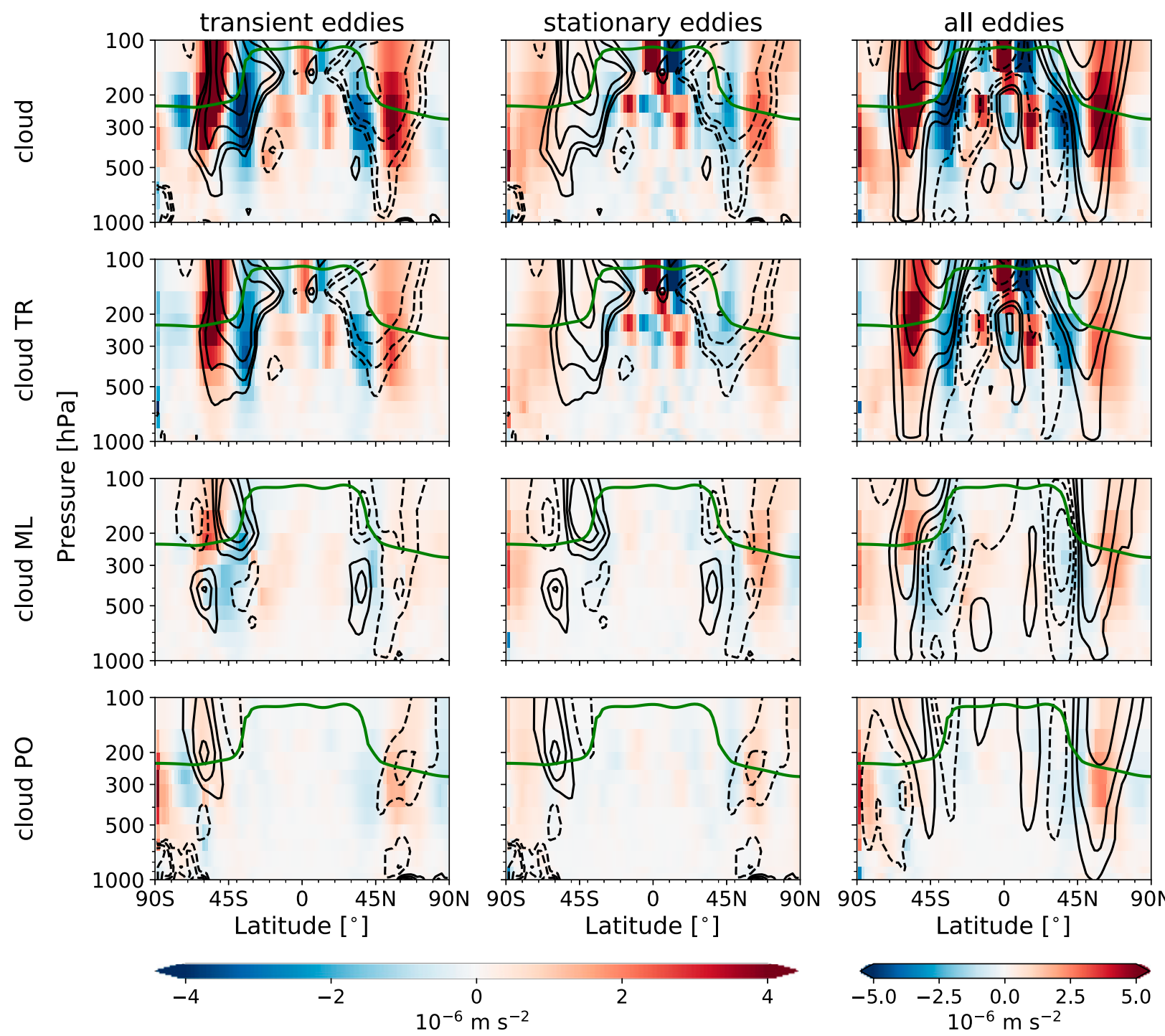

FIG. 10. Cloud impacts on the response of the (left) transient, (center) stationary, and (right) total eddy momentum flux convergence (shading), overlaid by responses in the meridional temperature gradient (contours in the first and second columns; contour intervals are as in Fig. 9) or responses in the zonal wind (contours in the third column). The contours for the zonal wind are in intervals of $1 \mathrm{~m} \mathrm{~s}^{-1}$ between -4 and $-1 \mathrm{~m} \mathrm{~s}^{-1}$ and between 1 and $4 \mathrm{~m} \mathrm{~s}^{-1}$, with additional contours for \pm 0.5 and $\pm 0.25 \mathrm{~m} \mathrm{~s}^{-1}$ for the global and tropical cloud impacts and $\pm 0.5, \pm 0.25$, and $\pm 0.1 \mathrm{~m} \mathrm{~s}^{-1}$ for the midlatitude and polar cloud impacts. The green lines show the tropopause height in the control simulation.

are broadly consistent with the influence of cloudradiative changes on upper-tropospheric baroclinicity. For example, increases in the upper-tropospheric meridional temperature gradients due to cloud-radiative changes are associated with 1) anomalously poleward eddy fluxes of heat and thus vertical wave propagation and 2) anomalous eddy momentum flux convergence aloft consistent with enhanced stirring of the uppertropospheric flow. These relationships are most prevalent for the tropical cloud changes and weaker for the midlatitude and polar cloud impacts. The transient component of the eddy momentum fluxes dominates the annual-mean global and tropical cloud impacts, whereas the stationary component is also important for the midlatitude and polar cloud impacts in the Northern Hemisphere.

In this study, we found that tropical cloud changes dominate the $850 \mathrm{hPa}$ zonal wind, jet strength, and storm track responses and are very important for the jet shift. A more detailed investigation of the impact of different tropical regions seems necessary to be able to conclude which tropical region is most important for the cloud 
impact on the midlatitude circulation response to global warming. Additionally, previous studies that investigated the cloud impact on the circulation response to global warming either analyzed the atmospheric pathway of the cloud impact by prescribing SST or the surface pathway of the cloud impact by coupling the atmospheric component of the model to a slab ocean. Future studies should investigate if and how the relative importance of global and regional cloud impacts changes if the atmospheric component of the model is coupled to an ocean model or if it is used as part of an Earth system model.

Acknowledgments. N.A. and A.V. are supported by the German Ministry of Education and Research (BMBF) and FONA: Research for Sustainable Development (www.fona.de) under grant agreement 01LK1509A. D.W.J.T. is supported by the U.S. National Science Foundation Climate and Large Scale Dynamics under Grants 1547003 and 1734251. J.G.P. thanks AXA research fund for support. N.A. thanks D.W.J.T. for hosting a threemonth visit at Colorado State University. The ICON simulations were carried out by N.A. at the Mistral supercomputer of the German Climate Computing Center (DKRZ) in Hamburg, Germany. This work contributes to the WCRP's Grand Challenge on Clouds, Circulation, and Climate Sensitivity and the BMBFfunded project " $\mathrm{HD}(\mathrm{CP})^{2}$ : High Definition Clouds and Precipitation for Advancing Climate Prediction".

Data availability statement. The output from the ICON model simulations is published at KITopen from Karlsruhe Institute of Technology (https:// doi.org/10.5445/IR/1000094317 and https://doi.org/ 10.5445/IR/1000120129).

\section{REFERENCES}

Albern, N., A. Voigt, and J. G. Pinto, 2019: Cloud-radiative impact on the regional responses of the midlatitude jet streams and storm tracks to global warming. J. Adv. Model. Earth Syst., 11, 1940-1958, https://doi.org/10.1029/2018MS001592.

Barnes, E. A., and L. M. Polvani, 2013: Response of the midlatitude jets and of their variability to increased greenhouse gases in CMIP5 models. J. Climate, 26, 7117-7135, https://doi.org/ 10.1175/JCLI-D-12-00536.1.

, and D. W. J. Thompson, 2014: Comparing the roles of barotropic versus baroclinic feedbacks in the atmosphere's response to mechanical forcing. J. Atmos. Sci., 71, 177-194, https://doi.org/10.1175/JAS-D-13-070.1.

, D. L. Hartmann, D. M. W. Frierson, and J. Kidston, 2010: Effect of latitude on the persistence of eddy-driven jets. Geophys. Res. Lett., 37, L11804, https://doi.org/10.1029/2010 GL043199.

Blackmon, M. L., 1976: A climatological spectral study of the 500 mb geopotential height of the Northern Hemisphere. J. Atmos. Sci.,
33, 1607-1623, https://doi.org/10.1175/1520-0469(1976)033<1607: ACSSOT $>2.0 . \mathrm{CO} 2$.

Bony, S., and Coauthors, 2015: Clouds, circulation and climate sensitivity. Nat. Geosci., 8, 261-268, https://doi.org/10.1038/ ngeo2398.

Brayshaw, D. J., B. J. Hoskins, and M. Blackburn, 2009: The basic ingredients of the North Atlantic storm track. Part I: Land-sea contrast and orography. J. Atmos. Sci., 66, 2539-2558, https:// doi.org/10.1175/2009JAS3078.1.

Butler, A. H., D. W. J. Thompson, and R. Heikes, 2010: The steadystate atmospheric circulation response to climate change-like thermal forcings in a simple general circulation model. J. Climate, 23, 3474-3496, https://doi.org/10.1175/2010JCLI3228.1.

,-- , and T. Birner, 2011: Isentropic slopes, downgradient eddy fluxes, and the extratropical atmospheric circulation response to tropical tropospheric heating. J. Atmos. Sci., 68, 2292-2305, https://doi.org/10.1175/JAS-D-10-05025.1.

Ceppi, P., and D. L. Hartmann, 2015: Connections between clouds, radiation, and midlatitude dynamics: A review. Curr. Climate Change Rep., 1, 94-102, https://doi.org/10.1007/s40641-015-0010-x.

$\longrightarrow$, and -2016 : Clouds and the atmospheric circulation response to warming. J. Climate, 29, 783-799, https://doi.org/ 10.1175/JCLI-D-15-0394.1.

— , and T. G. Shepherd, 2017: Contributions of climate feedbacks to changes in atmospheric circulation. J. Climate, 30, 90979118, https://doi.org/10.1175/JCLI-D-17-0189.1.

—, Y.-T. Hwang, X. Liu, D. M. W. Frierson, and D. L. Hartmann, 2013: The relationship between the ITCZ and the Southern Hemispheric eddy-driven jet. J. Geophys. Res., 118 , 5136-5146, https://doi.org/10.1002/jgrd.50461.

Chen, G., and I. M. Held, 2007: Phase speed spectra and the recent poleward shift of Southern Hemisphere surface westerlies. Geophys. Res. Lett., 34, L21805, https://doi.org/10.1029/2007GL031200.

- J. Lu, and D. M. W. Frierson, 2008: Phase speed spectra and the latitude of surface westerlies: Interannual variability and global warming trend. J. Climate, 21, 5942-5959, https:// doi.org/10.1175/2008JCLI2306.1.

Dickinson, R. E., 1969: Vertical propagation of planetary Rossby waves through an atmosphere with Newtonian cooling. J. Geophys. Res., 74, 929-938, https://doi.org/10.1029/JB074i004p00929.

Gates, W. L., 1992: AMIP: The Atmospheric Model Intercomparison Project. Bull. Amer. Meteor. Soc., 73, 1962-1970, https://doi.org/ 10.1175/1520-0477(1992)073<1962:ATAMIP>2.0.CO;2.

Graversen, R., and M. Wang, 2009: Polar amplification in a coupled climate model with locked albedo. Climate Dyn., 33, 629-643, https://doi.org/10.1007/s00382-009-0535-6.

Hartmann, D. L., and K. Larson, 2002: An important constraint on tropical cloud-climate feedback. Geophys. Res. Lett., 29, 1951, https://doi.org/10.1029/2002GL015835.

Harvey, B. J., L. C. Shaffrey, and T. J. Woollings, 2015: Deconstructing the climate change response of the Northern Hemisphere wintertime storm tracks. Clim. Dyn., 45, 2847 2860, https://doi.org/10.1007/S00382-015-2510-8.

Held, I. M., 1975: Momentum transport by quasi-geostrophic eddies. J. Atmos. Sci., 32, 1494-1497, https://doi.org/10.1175/ 1520-0469(1975)032<1494:MTBQGE>2.0.CO;2.

Hoskins, B. J., and D. J. Karoly, 1981: The steady linear response of a spherical atmosphere to thermal and orographic forcing. J. Atmos. Sci., 38, 1179-1196, https://doi.org/10.1175/15200469(1981)038<1179:TSLROA $>2.0$. CO;2.

_ , and P. J. Valdes, 1990: On the existence of storm-tracks. J. Atmos. Sci., 47, 1854-1864, https://doi.org/10.1175/15200469(1990)047<1854:OTEOST>2.0.CO;2. 
Kidston, J., S. M. Dean, J. A. Renwick, and G. K. Vallis, 2010: A robust increase in the eddy length scale in the simulation of future climates. Geophys. Res. Lett., 37, L03806, https:// doi.org/10.1029/2009GL041615.

_ , G. K. Vallis, S. M. Dean, and J. A. Renwick, 2011: Can the increase in the eddy length scale under global warming cause the poleward shift of the jet streams? J. Climate, 24, 37643780, https://doi.org/10.1175/2010JCLI3738.1.

Kushner, P. J., and I. M. Held, 1998: A test, using atmospheric data, of a method for estimating oceanic eddy diffusivity. Geophys. Res. Lett., 25, 4213-4216, https://doi.org/10.1029/1998GL900142.

— _ _ and T. L. Delworth, 2001: Southern Hemisphere atmospheric circulation response to global warming. J. Climate, 14, 2238-2249, https://doi.org/10.1175/1520-0442(2001)014<0001 SHACRT $>2.0 . \mathrm{CO} ; 2$.

Li, Y., D. W. J. Thompson, and S. Bony, 2015: The influence of atmospheric cloud radiative effects on the large-scale atmospheric circulation. J. Climate, 28, 7263-7278, https://doi.org/ 10.1175/JCLI-D-14-00825.1.

,,,--- and T. M. Merlis, 2019: Thermodynamic control on the poleward shift of the extratropical jet in climate change simulations: The role of rising high clouds and their radiative effects. J. Climate, 32, 917-934, https://doi.org/10.1175/JCLID-18-0417.1.

Lindzen, R. S., and B. Farrell, 1980: A simple approximate result for the maximum growth rate of baroclinic instabilities. J. Atmos. Sci., 37, 1648-1654, https://doi.org/10.1175/15200469(1980)037<1648:ASARFT>2.0.CO;2.

Lorenz, D. J., and E. T. DeWeaver, 2007: Tropopause height and zonal wind response to global warming in the IPCC scenario integrations. J. Geophys. Res., 112, D10119, https://doi.org/ 10.1029/2006JD008087.

Lu, J., G. Chen, and D. M. W. Frierson, 2008: Response of the zonal mean atmospheric circulation to El Niño versus global warming. J. Climate, 21, 5835-5851, https://doi.org/10.1175/ 2008JCLI2200.1.

Manabe, S., and R. T. Wetherald, 1987: Large-scale changes of soil wetness induced by an increase in atmospheric carbon dioxide. J. Atmos. Sci., 44, 1211-1236, https://doi.org/10.1175/15200469(1987)044<1211:LSCOSW > 2.0.CO;2.

Mauritsen, T., R. G. Graversen, D. Klocke, P. L. Langen, B. Stevens, and L. Tomassini, 2013: Climate feedback efficiency and synergy. Climate Dyn., 41, 2539-2554, https:// doi.org/10.1007/s00382-013-1808-7.

O'Gorman, P. A., 2010: Understanding the varied response of the extratropical storm tracks to climate change. Proc. Natl. Acad. Sci. USA, 107, 19176-19180, https://doi.org/10.1073/pnas. 1011547107.

Peixoto, J. P., and A. H. Oort, 1992: Physics of Climate. AIP Press, $520 \mathrm{pp}$.

Pinto, J. G., U. Ulbrich, G. C. Leckebusch, T. Spangehl, M. Reyers, and S. Zacharias, 2007: Changes in storm track and cyclone activity in three SRES ensemble experiments with the ECHAM5/ MPI-OM1 GCM. Climate Dyn., 29, 195-210, https:/doi.org/ 10.1007/s00382-007-0230-4

Shaw, T. A., 2019: Mechanisms of future predicted changes in the zonal mean mid-latitude circulation. Curr. Climate Change Rep., 5, 345-357, https://doi.org/10.1007/S40641-019-00145-8.
- and Coauthors, 2016: Storm track processes and the opposing influences of climate change. Nat. Geosci., 9, 656-664, https:// doi.org/10.1038/ngeo2783.

Simpson, I. R., M. Blackburn, and J. D. Haigh, 2009: The role of eddies in driving the tropospheric response to stratospheric heating perturbations. J. Atmos. Sci., 66, 1347-1365, https:// doi.org/10.1175/2008JAS2758.1.

— T. A. Shaw, and R. Seager, 2014: A diagnosis of the seasonally and longitudinally varying midlatitude circulation response to global warming. J. Atmos. Sci., 71, 2489-2515, https://doi.org/10.1175/JAS-D-13-0325.1.

Singh, M. S., and P. A. O'Gorman, 2012: Upward shift of the atmospheric general circulation under global warming: Theory and simulations. J. Climate, 25, 8259-8276, https://doi.org/ 10.1175/JCLI-D-11-00699.1.

Slingo, A., and J. M. Slingo, 1988: The response of a generalcirculation model to cloud longwave radiative forcing. Part I: Introduction and initial experiments. Quart. J. Roy. Meteor. Soc., 114, 1027-1062, https://doi.org/10.1002/qj.49711448209.

Thompson, D. W. J., S. Bony, and Y. Li, 2017: Thermodynamic constraint on the depth of the global tropospheric circulation. Proc. Natl. Acad. Sci. USA, 114, 8181-8186, https://doi.org/ 10.1073/pnas.1620493114.

Vallis, G. K., 2017: Atmospheric and Oceanic Fluid Dynamics: Fundamentals and Large-Scale Circulation. 2nd ed. Cambridge University Press, https://doi.org/10.1017/9781107588417, 964 pp. P. Zurita-Gotor, C. Cairns, and J. Kidston, 2015: Response of the large-scale structure of the atmosphere to global warming. Quart. J. Roy. Meteor. Soc., 141, 1479-1501, https://doi.org/10.1002/qj.2456.

Voigt, A., and T. A. Shaw, 2015: Circulation response to warming shaped by radiative changes of clouds and water vapor. Nat. Geosci., 8, 102-106, https://doi.org/10.1038/ngeo2345.

, and - 2016: Impact of regional atmospheric cloudradiative changes on shifts of the extratropical jet stream in response to global warming. J. Climate, 29, 8399-8421, https:// doi.org/10.1175/JCLI-D-16-0140.1.

_ , and N. Albern, 2019: No cookie for climate change. Geophys. Res. Lett., 46, 14 751-14 761, https://doi.org/10.1029/2019GL084987.

,$- \ldots$, and G. Papavasileiou, 2019: The atmospheric pathway of the cloud-radiative impact on the circulation response to global warming: Important and uncertain. J. Climate, 32, 30513067, https://doi.org/10.1175/JCLI-D-18-0810.1.

Woollings, T., J. M. Gregory, J. G. Pinto, M. Reyers, and D. J. Brayshaw, 2012: Response of the North Atlantic storm track to climate change shaped by ocean-atmosphere coupling. Nat. Geosci., 5, 313-317, https://doi.org/10.1038/ngeo1438.

Yin, J. H., 2005: A consistent poleward shift of the storm tracks in simulations of 21st century climate. Geophys. Res. Lett., 32, L18701, https://doi.org/10.1029/2005GL023684.

Zängl, G., D. Reinert, P. Ripodas, and M. Baldauf, 2015: The ICON (ICOsahedral Non-hydrostatic) modelling framework of DWD and MPI-M: Description of the non-hydrostatic dynamical core. Quart. J. Roy. Meteor. Soc., 141, 563-579, https:// doi.org/10.1002/qj.2378.

Zappa, G., B. J. Hoskins, and T. G. Shepherd, 2015: Improving climate change detection through optimal seasonal averaging: The case of the North Atlantic jet and European precipitation. J. Climate, 28, 6381-6397, https://doi.org/10.1175/JCLI-D-14-00823.1. 